\title{
Saúde pública e saúde coletiva: campo e núcleo de saberes e práticas
}

Public health and collective health:

field and core area for knowledge and practice

Gastão Wagner de Sousa Campos ${ }^{1}$

\begin{abstract}
This paper discusses collective health knowledge and practices field and its core based on a dialectics method, beyond positivism and structuralism, to carry out a critical view towards their trends in assuming a transcendent position about the health field. From this analysis on, suggestions for debating are elaborated, taking the historical and social elements of concrete subjects, in their main relation to what is termed collective health.

Key words Public Health; Collective Health; Constructivism
\end{abstract}

Resumo O artigo discute o campo e o núcleo de saberes e de práticas da saúde coletiva a partir de um metodologia dialética, pensando-a para além do positivismo e do estruturalismo e fazendo uma crítica à sua tendência de assumir posição de transcendência sobre o campo da saúde. A partir dessa análise são elaboradas sugestões para debate, relacionadas centralmente com saúde coletiva entendida como construção sociohistórica de sujeitos concretos.

Palavras-chave Saúde Pública; Saúde Coletiva; Construtivismo

${ }^{1}$ Departamento de 
Sinais de glória e sintomas de crise: algumas questões sobre a saúde coletiva

Repensar a saúde coletiva, aproveitando-se da história e da tradição da saúde pública. Entendê-la tanto como um campo científico quanto como um movimento ideológico em aberto, conforme sugeriram Almeida Filho e Paim (1999). Um movimento que, sem dúvida, no Brasil, contribuiu decisivamente para a construção do Sistema Único de Saúde (SUS) e para enriquecer a compreensão sobre os determinantes do processo saúde e doença. Mas também reconhecer que o modo como vem ocorrendo sua institucionalização tem bloqueado a reconstrução crítica de seus próprios saberes e práticas, provocando uma crise de identidade manifesta em sua fragmentação e diluição como campo científico. São estas as questões aqui tratadas.

As questões enunciadas têm como sintomas uma série de dilemas que vêm sendo analisados pelos especialistas: a saúde coletiva teria criado um novo paradigma, negando e superando o da medicina e o da antiga saúde pública? Saúde coletiva corresponderia a todo o campo da saúde, ou apenas a uma parte? A expansão do SUS provocaria um crescimento automático das práticas de saúde coletiva? Saúde pública abarcaria todo o sistema estatal de saúde, indicando ser ela o lado contrário de práticas privadas? Ou nomearia também uma profissão e um campo de práticas? A noção de produção social da saúde, central à saúde coletiva, seria oposta ou complementar à de história natural do processo saúde e doença, adotada pela clínica como modelo explicativo?

Mais do que buscar definições formais, importa reconhecer que uma teoria e seus conceitos têm implicações, ainda que não absolutas, sobre as práticas sociais (Donnangelo, 1983; Bourdieu, 1983; Testa, 1993).

Busca-se, portanto, um método de reflexão para analisar a saúde coletiva não somente baseado em a priori teórico, mas também em compromisso concreto com a produção de saúde, já que a produção de saúde é função e finalidade essencial sem a qual não se está autorizado a falar em trabalho em saúde. Nesse sentido, a ambigüidade e a ubiqüidade do conceito de saúde coletiva têm também contribuído para a fragmentação e para o enfraquecimento do seu campo de saber e de práticas.

Admite-se hoje a inevitável existência de uma certa sobreposição de limites entre as dis- ciplinas. O mesmo ocorrendo com os campos de prática. Nesses termos, quase todo campo científico ou de práticas seria interdisciplinar e multiprofissional. Guattari e Deleuze (1976) na filosofia, na política e na clínica, McNeill e Freiberger (1993) na matemática, assim como vários outros autores "pós-modernos" têm criticado o sentido absoluto com que se tomam algumas noções, como a de dentro e fora, identidade e diferença, coletivo e individual, macro e micro. Mesmo concordando com esses pensadores, parece que este borramento de limites indicaria mais uma impossibilidade de fecharse em copas do que a extinção, com a conseqüente fusão, de todas as disciplinas, profissões e especialidades.

Para escapar a este paradoxo - o do isolamento paranóico ou o da fusão esquizofrênica -, um grupo de pesquisadores sugeriu alterações nos conceitos de núcleo e de campo (Campos, et al., 1997). A institucionalização dos saberes e sua organização em práticas se daria mediante a conformação de núcleos e de campos. Núcleo como uma aglutinação de conhecimentos e como a conformação de um determinado padrão concreto de compromisso com a produção de valores de uso. O núcleo demarcaria a identidade de uma área de saber e de prática profissional; e o campo, um espaço de limites imprecisos onde cada disciplina e profissão buscariam em outras apoio para cumprir suas tarefas teóricas e práticas (Campos, 2000).

Esses conceitos diferem da elaboração de Bourdieu $(1983,1992)$ sobre campo e corpus já que os autores modificaram o sentido polar e antagônico atribuído aos dois termos. Para Bourdieu campo intelectual se conformaria como espaço aberto, ainda quando submetido a conflitos de origem externa e interna. Entretanto, nos corpus verificar-se-ia o seu subseqüente fechamento em disciplinas, quando ocorreria a monopolização do saber e da gestão das práticas por agrupamentos de especialistas. A formação de disciplinas (corpus) no campo religioso, político ou científico, ocorreria com o fechamento ou institucionalização de parte do campo, com a conseqüente criação de aparelhos de controle sobre as práticas sociais a ele referentes.

Um núcleo, ao contrário, indicaria uma aglutinação, uma determinada concentração de saberes e de práticas, sem, contudo, indicar um rompimento radical com a dinâmica do campo. Igual à noção de corpus, a de núcleo também parte da necessidade, e da inevitabilidade 
de se construírem identidades sociais para as profissões e para os campos de saber. Mas, ao contrário, sugere a possibilidade de que essa institucionalização poderia acontecer de modo mais flexível e aberto (Onocko, 1999). Enfim, não haveria como escapar-se à institucionalização do saber e à administração organizada das práticas sociais. Porém, elas poderiam ser organizadas de forma democrática, sendo estruturadas de forma a permanecerem abertas a distintos campos de influência. O conceito de corpus (disciplina) enfatiza a concentração de poder e a tendência de fechamento das instituições. A noção de núcleo valoriza a democratização das instituições, ou seja, ressalta sua dimensão socialmente construída, sugerindo que a escolha de seus caminhos funcione como uma possibilidade e não como uma ocorrência automática. De outra forma, aos sujeitos não restaria outra opção que a de permanecerem em desestruturação à espera dos automatismos dos campos em fase instituinte; ou, ao contrário a de se prenderem a disciplinas fechadas.

Tanto o núcleo quanto o campo seriam, pois, mutantes e se interinfluenciariam, não sendo possível detectar-se limites precisos entre um e outro. Contudo, no núcleo, haveria uma aglutinação de saberes e práticas, compondo uma certa identidade profissional e disciplinar. Metaforicamente, os núcleos funcionariam em semelhança aos círculos concêntricos que se formam quando se atira um objeto em água parada. O campo seria a água e o seu contexto.

Partindo do marco conceitual exposto, seria pertinente perguntar qual a identidade da saúde coletiva? Ou seja, qual o seu núcleo de saberes e de práticas? E mais, em que campo de interinfluência ela estaria mergulhada? Em decorrência, acrescem-se outros dilemas aos já citados: quem é o agente que faz saúde coletiva? Haveria um agente especializado? Sem dúvida, médicos, a equipe de saúde, o governo, a comunidade, muitos, potencialmente, produzem saúde. Todos que produzem saúde seriam agentes da saúde coletiva ou da saúde pública? Haveria um núcleo de saber especializado e um agente específico, nuclearmente encarregado de produzir ações de saúde pública? Haveria necessidade social de formá-lo? Haveria possibilidade histórica concreta de que seu trabalho fosse requisitado?

A necessidade reflexiva autoriza a prosseguir no esforço crítico dos que romperam com o conceito tradicional da saúde pública e investiram na construção da teoria e das práticas da saúde coletiva. Apesar do que já se escreveu sobre esta mudança e inclusive sobre as ambigüidades (Donnangelo, 1983; Nunes, 1986; Minayo, 1991; Paim, 1992) valeria ainda insistir na pergunta: o que aquela troca de nomes revelou de novo? Que rupturas, de fato, aconteceram? O que existe de continuidade? Talvez seja o momento de analisar algumas experiências construídas pela velha saúde pública que o radicalismo inerente ao momento de fundação de uma nova proposta impediu examinar com mais cuidado. Inclusive, é importante aprofundar os motivos pelos quais, depois de tanto desenvolvimento teórico e da incorporação de uma sofisticada trama de categorias sociológicas, a saúde coletiva brasileira, ao propor modos de intervenção, continua tributária, não da teoria crítica que construiu, mas de um pensamento sistêmico bastante pragmático e instrumental, muito à moda e gosto dos anglo-saxões.

\section{A saúde coletiva para além do positivismo, do estruturalismo e de uma posição de transcendência sobre o campo da saúde}

Com certeza, não caberia abandonar a trilha dos fundadores, mas seguir-lhes as pegadas, afinal foram pioneiros na crítica ao positivismo, constitutivo básico das práticas sanitárias tradicionais. Para Antônio Ivo de Carvalho (1996) a saúde coletiva nasceu da crítica ao positivismo e... à saúde pública tradicional, constituída à imagem e semelhança da tecno-ciência e do modelo biomédico. Pois bem, apesar dessa origem, nota-se o recrudescer de um certo neopositivismo, advogando-se como método de trabalho, versões mais ou menos sofisticadas da teoria de sistemas (OPAS, 1992; Barata, R \& Barreto, M, 1996).

Quer pela insuficiência do pensamento social incorporado à saúde coletiva para impulsionar práticas e projetos sanitários concretos, quer pela pressão exercida pelas agências financiadoras e pela própria instituição universitária no sentido de que a saúde coletiva adote, em sua construção teórica, normas e procedimentos padrões bastante assemelhados aos da medicina em particular ou aos da tecnociência em geral, observa-se um crescimento de prestígio do objetivismo na produção científica da área. Rever as relações entre sujeito e objeto (Carva- 
lho, 1996) continua sendo ainda uma tarefa crítica contemporânea, portanto.

Nunes (1996) descreveu que o termo Saúde Coletiva passou a ser utilizado, no Brasil, em 1979, quando um grupo de profissionais, oriundos da saúde pública e da medicina preventiva e social procuraram fundar um campo científico com uma orientação teórica, metodológica e política que privilegiava o social como categoria analítica. Agudelo e Nunes (1991), ainda que reconhecendo o papel decisivo do movimento da saúde coletiva no Brasil e em outros países da América do Sul, na incorporação do social à temática da saúde, não deixaram de apontar que tampouco esta expressão tem podido resolver totalmente a insuficiência das denominações em questão.

Para Carvalho (1996) a saúde coletiva, ao incorporar o social ao pensamento sanitário, tendeu a fazê-lo segundo cânones objetivistas preconizados pela escola estruturalista e pela tradição marxista: a subjetividade aqui admitida é aquela que brota da necessidade coletiva e que se organiza em sujeitos coletivos - no Estado, no partido, nas organizações classistas e comunitárias...

De fato, apesar de autores tão influentes como Testa (1993) e Donnangelo (1976) haverem divulgado análises em que a saúde pública aparecia como construção histórica e o exercício profissional como prática social, não há como não concordar com Carvalho quando aponta que o saber dominante em saúde coletiva tendeu a subestimar a importância dos sujeitos na construção do cotidiano e da vida institucional.

Finalmente, caberia reconhecer a tendência da saúde coletiva em confundir-se com todo o campo da saúde. Tal tendência indicaria uma visão de mundo fundada em categorias absolutas e transcendentais. Para alguns, a saúde coletiva se constitui numa espécie de metadiscurso supostamente capaz de criticar e reconstruir saberes e processos concretos de produção de saúde. Nesse sentido, ela forneceria metaexplicações auto-suficientes sobre a tríade saúde, doença e intervenção. Por outro lado, seu discurso constitutivo tenderia a hipervalorizar a determinação social dos processos saúde/doença, desqualificando os fatores de ordem subjetiva e biológica. Neste caso, a saúde coletiva não é vista como um modo de intervenção sobre o real mas como um novo paradigma ou um modelo alternativo aos demais.

O modelo denominado de vigilância em saúde (Mendes, 1993), por exemplo, proclama- se vinculado a um novo paradigma, o da promoção à saúde, imaginando que a incorporação do social à análise dos processos saúde e doença criaria práticas distintas, senão antagônicas, àquelas baseadas na história natural. Um novo modo de se produzir saúde, que negaria o modelo clínico e não um modo entre outros não necessariamente equivalentes, porém úteis, cada uma dentro de seus limites e especificidade.

Outro não tem sido o procedimento dominante na medicina, que desautoriza, em princípio, todo o saber e toda a prática sobre saúde, produzidos fora de sua própria racionalidade. Ao criticá-lo, com pertinência, a saúde coletiva tende a adotar a mesma postura totalitária e disciplinar. Para diversos autores, a epidemiologia e as ciências sociais explicariam o processo saúde/doença e fundariam um novo paradigma, com um modo de intervenção sobre a realidade que superaria - sempre em princípio! todos os outros existentes. De acordo com essa perspectiva a saúde coletiva não seria um saber, entre outros, sobre os modos como se produz saúde e doença; mas, o saber. Quase um novo paradigma. Alguns autores e mesmo documentos de organismos internacionais chegaram a anunciar o surgimento de um novo paradigma de promoção da saúde que superaria a influência do modelo clínico na organização dos serviços e práticas (Mendes, 1993; WHO, 1991).

Nesse trabalho não se sugere a possibilidade de completa superação das tendências descritas, o que significaria cair na mesma armadilha metodológica criticada. Tampouco pretende-se demonizá-las. Não há como se operar sem objetividade. As estruturas existem e influenciam a produção do campo da saúde: normas, saberes, culturas, sistemas, instituições. Além do mais, não há como desconhecer a importância (não a transcendência, apenas a importância) que saberes e práticas advindos da saúde coletiva tiveram e têm para a reformulação da clínica, da reabilitação e dos sistemas de saúde em geral. Donnangelo (1983) já havia demarcado que a saúde coletiva influenciava e apoiava práticas de distintas categorias e atores sociais, quer em temas ligados à organização da assistência, quer na compreensão dos próprios meandros da produção de saúde.

Busca-se, ao contrário, recuperar a velha dialética, verificando em que medida posições e pólos operam em regime de contradição ou de complementaridade. Assim, à promessa de objetivação asséptica do positivismo é preciso contrapor a subjetividade dos agentes sociais 
em todas as fases do processo saúde/doença/intervenção, inclusive quando da elaboração de conhecimentos e tecnologias. Jamais, contudo, deve-se abrir mão dessas linhas de análise. Ao peso das estruturas contrapõe-se a história que as produz, pela ação social de indivíduos, grupos e movimentos. Além do reconhecimento de que a saúde coletiva é um saber constitutivo e essencial a todas as práticas em saúde, é fundamental admitir que também se produzem conhecimentos, políticas e valores relevantes para saúde a partir de outros campos, como o da clínica ou o da reabilitação.

\section{Algumas palavras sobre a dialética}

A proposta que aqui se apresenta é de repensar a saúde coletiva filiando-se àquelas escolas filosóficas que sustentam a existência de relação dialética entre o pensar e o agir, entre o homem e o mundo, e entre os próprios homens, entre ser e não ser, ao mesmo tempo. Pensar criador e criatura embolados, todo o tempo, um ente produzindo por ele e por outros. Precisando melhor, é importante assumir que toda produção é uma co-produção em que o produtor é também modificado pelo produto.

O ser humano é parte inseparável do mundo, ainda que desfrutando de uma propriedade especial de se afastar dele. Ou seja conserva o poder da imanência assim como detém o poder de reflexão do sujeito para estranhar o mundo e modificá-lo, assim como para modificar a si e aos outros. Jamais seres humanos poderiam destacar-se da condição material de pertencer a este mesmo mundo assim como não podem declinar do papel histórico de transformá-lo.

Marx pretendeu superar a dicotomia entre o materialismo mecanicista e o idealismo religioso ou voluntarista (Marx \& Engels, 1996); no entanto, poucos entre seus seguidores sustentaram essa tensão dialética entre objetividade e subjetividade, talvez, de fato, pouco trabalhada pelo velho revolucionário.

Possivelmente Gramsci tenha sido o discípulo que mais longe levou os desdobramentos decorrentes desta visão de mundo. Para este pensador, a vontade humana e a objetividade do mundo exterior seriam qualidades inseparáveis, uma a constituir e a influenciar a outra, durante todo o tempo. Por isso, ele valorizou a idéia de devenir: o homem devém, transforma-se continuamente com as transformações das relações sociais (Gramsci, 1978).
Outro estudioso que muito contribuiu para o desenvolvimento do pensamento dialético foi Henri Lefebvre. Este trabalho inclusive, vale-se do seu conceito de ser humano (sujeito) assim sintetizado por ele: A palavra Ser aparece... em dois sentidos a um tempo contraditórios e inseparáveis: o ser abstrato, vazio, indeterminado; $e$ o ser rico em determinações, desenvolvido (Lefebvre, 1995).

O termo ser humano indicaria, portanto, uma ambigüidade insanável: ser, pensado como uma identidade abstrata, substantiva, relativa à condição humana em geral ou a um indivíduo específico. Mas também indicando vira-ser, o verbo ser no sentido de devir; ou seja, o esforço existencial e a práxis social para se constituir como sujeito. Talvez, o gerúndio do verbo, uma pessoa ou um grupo sendo. Ser, sendo. Ser em transformação perene.

Alguns historiadores atribuem à intenção de driblar a censura fascista o hábito de Gramsci utilizar o termo filosofia da práxis para designar o marxismo. Ainda que movido por esse constrangimento, a escolha das palavras, parece-me, indicaria um compromisso espistemológico distinto da tradição marxista criticada por Carvalho (1996). Ou seja, Gramsci ressalta e propõe a adoção de um método de pensar que não anula as relações e influências mútuas entre abstrato e concreto; individual e coletivo; pensar e agir; ou tampouco, entre economia, política e psicologia; ou ciência e senso comum.

Lefebvre (1995) defendia que um bom método para pensar a vida deveria sempre obedecer a, pelo menos, quatro exigências. Primeira, o pensamento deveria sempre lidar com ambos os termos que a metafísica ou o objetivismo têm procurado separar. Assim, haveria que se descobrir relações entre o ser e o mundo, o social e o individual, entre essência e aparência, entre tudo e nada. Portanto, estaria vedado optar e não optar, de modo transcendente, por um dos extremos dessas polaridades.

Em segundo lugar, o pensamento somente se afirmaria como movimento, sendo, portanto, sempre incompleto. Se nem isso fosse esvaziado de qualquer verdade, jamais também portaria toda a verdade sobre as coisas. Terceiro, seria importante considerar o caráter contraditório inerente ao pensar e ao agir, exatamente porque a partir de deslocamentos sucessivos entre os termos dessa polaridade seria possível estabelecer-se alguma crítica ao modo como um dado processo se desenvolveu. Desde a prática se critica o saber; desde o conhecimento se cri- 
tica a práxis. Lefebvre argumentava ainda que contradição não significa absurdo, já que tampouco seria possível eliminar seus dois pólos. Sugeria ainda usar-se o contraditório para enriquecer o saber, na medida que isso significaria descobrir um complemento de determinação.

Por último, ele negava transcendência tanto à consciência do sujeito quanto ao mundo objetivo, lembrando que conhecimento e mundo são ao mesmo tempo interiores e exteriores aos sujeitos (Lefebvre, 1995).

Inúmeros pensadores vêm desenvolvendo esforços para escapar à rigidez quer do objetivismo, quer do subjetivismo. Hegel referia-se à consciência infeliz daqueles que colocam sua vida nas mãos dos outros. Considerava-os seres presos à determinação do meio natural ou social e, portanto, impotentes para reagir contra o estabelecido criando algo novo (Hegel, 1974).

Foge ao objetivo deste trabalho reconstruir de maneira sistemática a história da dialética; mas, sem dúvida, dentro desta trajetória valeria destacar Sartre, Merleau-Ponty e o já comentado Bourdieu. O primeiro sugeriu conceitos para articular as estruturas de determinação dos sujeitos à sua própria capacidade de intervenção sobre esses determinantes. Particularmente, as categorias de grupo serial, projeto e grupo sujeito (Sartre, 1963) seriam fundamentais para repensar a saúde coletiva. Merleau-Ponty buscou articular psicologia e sociologia, modificando e reconstruindo uma série de conceitos originários da antropologia, do marxismo ou da ciência política, para aplicá-los em problemas antes tomados exclusivamente pela psicanálise, psicodrama, psicologia, e vice-versa (Merleau-Ponty, 1990).

A saúde coletiva, em analogia ao trabalho de Merleau-Ponty e dos mal denominados freud-marxistas, poderia escapar aos limites do positivismo e do estruturalismo, articulando teorias e práticas do campo da política e da gestão com saberes e experiências originários da psicanálise, pedagogia e análise institucional. Combinar política, gestão e epidemiologia (disciplinas que fazem parte da tradição da saúde coletiva) com clínica, psicanálise, pedagogia e análise institucional.

Marilena Chaui ressalta a crítica elaborada por Ponty ao pensamento ocidental, que seria um pensamento de sobrevôo, e que imporia uma separação entre o mundo e a consciência ao reduzir o real a um dos pólos da dicotomia sujeito-objeto. Neste sentido, ele discordaria tanto da pretensão transcendental do cientificismo, do desejo da filosofia de dominar e controlar totalmente a consciência ou a realidade exterior (Chaui, 1989).

Passando ao campo das práticas sociais, parece que foram as escolas de psicologia e da pedagogia que mais amplamente aplicaram perspectivas análogas em sua prática cotidiana. Em Freud é possível identificar uma recusa em optar por qualquer dos pólos responsáveis pela fragmentação contraditória dos sujeitos. Entre consciente e inconsciente ele nunca deixou de trabalhar em perspectiva dinâmica, em que lógicas distintas estariam todo o tempo impondo conflitos mais ou menos dilacerantes às pessoas (Freud, 1969). E o que seria a psicanálise senão um método consciente (racional e deliberado) para se lidar com o inconsciente e a incoerência constitutivos de todo e qualquer sujeito? Entre princípio de realidade e desejo sempre haveria espaço para algum grau de determinação e de influência sujeito, aprisionado entre essas linhas de força. Sem dúvida, a psicanálise e sua aplicação a grupos e instituições têm uma importante contribuição à uma teoria que pensasse a saúde coletiva como uma construção sociohistórica de sujeitos.

Diferentes autores enfatizaram o tema da intersubjetividade e o papel da inter-relação na constituição dos Sujeitos. Para Winnicott, por exemplo, somente haveria um sujeito intersubjetivo, ao mesmo tempo autoproduzido e produto das relações humanas (Ogden, 1996). Outra corrente que trabalhou a inseparabilidade do sujeito e do objeto, do coletivo e do indivíduo, foi a que se convencionou denominar construtivismo social. Trata-se de um movimento amplo, com limites imprecisos e importantes diferenças entre seus aderentes, mas que, em linhas gerais, sugere que o conhecimento é resultado da relação dialética entre o que Vygostsky denominou de atividades interpessoais (relações sociais as mais variadas) e atividades interpessoais (capacidade de ação reflexiva do próprio sujeito). De Vygostsky, no começo do século XX, a Paulo Freire, inúmeros autores elaboraram o denominado construtivismo sociohistórico, com concepções perfeitamente aplicáveis à saúde coletiva, conforme o vem demonstrando cientistas e profissionais ligados à denominada educação em saúde (Valla, 1999; Vasconcelos, 1999).

O construcionismo trabalha com a hipótese de uma eterna reconstrução das pessoas, a qual ocorreria em virtude da interação dos sujeitos com o mundo e dos sujeitos entre si. Porém, es- 
ta capacidade se desenvolveria, fundamentalmente, pela elaboração reflexiva de experiências, por meio do que o ser humano escaparia ao ciclo vicioso da determinação puramente biológica ou estrutural (Matui, 1995; Van der Veer \& Valsiner, 1996).

Então, caberia (seria possível?) inventar mundos, organizações e instituições (uma saúde pública, por exemplo) que produzissem não objetos/sujeitados, mas seres com potencial para pensar refletir ou analisar e agir com algum grau de autonomia em relação aos seus determinantes, fossem eles externos ou internos, conjunturais ou estruturais.

Os saberes e práticas apoiados no positivismo ou no estruturalismo reforçam a polaridade objeto das pessoas, por intervirem sobre os seres reduzidos à condição de receptores. Ainda que, na prática, um máximo de coisificação seja impossível, distintas estratégias políticas, sanitárias e terapêuticas fundadas sobre essas duas correntes filosóficas buscam a progressiva redução dos coeficientes de liberdade e de autonomia dos sujeitos. A práxis social daí advinda reafirma, embora não como fatalidade, a tendência histórica das instituições oprimirem a dimensão singular de cada sujeito ou os interesses e necessidades dos grupos dominados.

As práticas sociais, todas elas - a clínica, a saúde pública, a pedagogia, a gestão e a política, poderiam produzir a infinidade de matizes entre controle social (seres dominados) ou autonomia (cidadãos com liberdade relativa). Essas práticas operam, em potencial, tanto em prol de reduzir pessoas à condição de objetos sujeitados a algum poder, quanto no sentido de multiplicar as possibilidades de sujeitos viverem mais livremente. Essa liberdade significaria que, embora condicionados ao contexto e a compromissos, estariam aptos a lidar com autonomia relativa diante da objetividade das coisas e das relações sociais.

\section{O campo da saúde como uma matriz}

Dentro de um pensamento dialético a saúde coletiva seria um pedaço do campo da saúde. Valendo-se de imagens, talvez poder-se-ia projetar o campo da saúde como uma matriz em que a saúde coletiva fosse uma parte, em distintos planos de inserção. Desses, pelo menos dois são comentados neste artigo: a saúde coletiva, como movimento intelectual e moral; e a saúde coletiva como um núcleo, uma concen- tração nuclear de saberes e práticas. Um núcleo co-produzido por miríades de inter-relações com o campo e, ao mesmo tempo, um núcleo co-produtor desse mesmo campo.

Qual seria o núcleo da saúde coletiva? O apoio aos sistemas de saúde, à elaboração de políticas e à construção de modelos; a produção de explicações para os processos saúde/enfermidade/intervenção; e, talvez seu traço mais específico, a produção de práticas de promoção e prevenção de doenças. Qual o semblante do núcleo de saberes e práticas da saúde coletiva, então? Repito, semblante, sinal de identificação, e não um diferencial absoluto! Talvez a sua concentração em problemas de saúde com repercussão coletiva? Quem sabe um certo modo predominante de operar, um modo de intervenção centrado na promoção e na prevenção?

De qualquer modo, não o todo, mas uma parte. Uma parte dinâmica e com inserção e interferência no campo da saúde em pelo menos dois planos. Em um plano horizontal, em que saberes e práticas comporiam parte dos saberes e práticas de outras categorias e atores sociais. Assim, todas as profissões de saúde, as nucleadas na clínica ou na reabilitação ou no cuidado, todas, em alguma medida, deveriam incorporar em sua formação e em sua prática elementos da saúde coletiva. Um movimento cultural conforme o sugerido por Donnangelo (1976) há quase vinte anos e conforme veio ocorrendo dentro do chamado movimento de reforma sanitária. Assim, a saúde mental, a neurologia, a saúde da criança, dentre outras áreas, iriam se transformando também em conseqüência de aportes oriundos da saúde pública. Nessa perspectiva, a missão da saúde coletiva seria a de influenciar a transformação de saberes e práticas de outros agentes, contribuindo para mudanças do modelo de atenção e da lógica com que funcionam os serviços de saúde em geral.

A outra inserção na matriz seria vertical: a saúde coletiva (ou saúde pública) como uma área específica de intervenção. Uma área especializada e com valor de uso próprio, diferente da clínica ou de outras áreas de intervenção. Um espaço que para se institucionalizar necessitaria de definições formais: curso básico de formação, postos de trabalho no setor público e privado, associações de representação corporativa, todo o acervo instituinte de uma área parafernália bastante mais pesada do que o requerido por um movimento ideológico. 
O seu agente, quem seria e como operaria? Na saúde pública tradicional o sanitarista foi um especialista isolado, que trabalhava em programas verticais com forte grau de imposição autoritária. Para a Organização Pan-Americana de Saúde (OPAS, 1994) a principal característica do sanitarista seria sua capacidade de liderança, devendo os cursos de formação produzir líderes para o setor saúde. Trata-se de mais um exemplo concreto da postura arrogante e transcendente com que tem se posicionado a saúde pública diante dos outros setores que compõem o campo. Alguns adeptos do agir comunicativo, ao criticar tal perspectiva, chegam a caracterizar o trabalho do sanitarista como de advocacy, uma espécie de habilidoso defensor da saúde pública. Na prática, cumpriria o papel de um assessor de luxo, inerte e impotente frente à dureza do estabelecido. Muitos colocam em pauta, inclusive, a extinção da profissão e da especialidade, já que o estado, a sociedade e as equipes de saúde cumpririam todas as tarefas da saúde coletiva.

Talvez valesse a pena pensar o sanitarista como um agente de saúde pública, profissional com liderança ocasional, conforme os problemas e programas em questão, que trabalhasse em equipes interprofissionais mas com papel específico. Atuando tanto em projetos verticais, voltados para promoção e prevenção e coordenados por eles; quanto em outros de inserção matricial, intra-sistemas de saúde ou intersetoriais, em que o sanitarista seria um entre outros agentes.

No Brasil, nota-se um importante enfraquecimento da vertente da saúde pública pensada como especialidade. $\mathrm{O}$ aparelho formador em saúde coletiva tem privilegiado o mestrado e o doutorado, ou cursos de extensão voltados para a equipe de saúde em geral (Nunes, 1996), em detrimento da formação de especialistas e de residentes. Há, até mesmo, indefinição de critérios para os diferentes níveis e controvérsia sobre conteúdos e, portanto, descontrole sobre a qualidade dos profissionais autorizados exercerem as atividades de saúde coletiva. No caso de se adotar a primeira acepção, para saúde coletiva, considerando-se sua inserção horizontal, tão contrário a especialização seria fato sem importância, já que seu exercício seria tarefa de todos os profissionais de saúde e mesmo de toda a população.

$\mathrm{Na}$ realidade, seria importante combinar as duas perspectivas: tanto socializar saberes e práticas, quanto assegurar a existência de espe- cialistas capazes de produzir saberes mais sofisticados sobre saúde pública e de intervir em situações mais complexas.

\section{Considerações a respeito de uma teoria sobre a produção de saúde}

Uma teoria sobre a produção de saúde deveria apoiar todos as práticas sanitárias. Essa teoria, portanto, seria construída para todo o campo da saúde. Não para ser somente utilizada, mas também desenvolvida com a contribuição dialógica de toda a área e transbordando a fronteira do sistema sanitário propriamente. Mais que isso, tal teoria deveria incorporar, em sua racionalidade, todos os mecanismos sociais pelos quais se geram saúde e enfermidade.

Pois bem, nesse sentido, a construção de uma teoria sobre a produção de saúde ou sobre o processo saúde/enfermidade/intervenção não deveria ser monopólio nem ferramenta exclusiva da saúde coletiva, mas de todo o campo. Não há como pensar a superação do paradigma biomédico sem a contribuição da própria clínica só com aportes da epidemiologia e das ciências sociais. Nem somente com o biológico e o subjetivo se podem pensar modelos e políticas de atenção integral à saúde. A clínica tem muito a ser criticada, mas tem também muito a dizer. O mesmo poder-se-ia comentar sobre a saúde coletiva. Não há como repensar suas práticas desconhecendo o acervo da biologia, da psicologia e da clínica. Como pensar a AIDS ignorando ou a cultura ou o funcionamento concreto dos serviços de saúde, ou o comportamento do vírus, ou a potência dos imunobiológicos ou dos tratamentos medicamentosos?

Portanto, uma teoria do processo saúde/ doença/intervenção deveria constituir o acervo básico e fundamental de todos os campos científicos e de todas as práticas que compõem o campo mais amplo da saúde. Este entendimento atenua a pretensão de transcendência e de auto-suficiência da saúde coletiva. Uma teoria sobre a produção de saúde funcionaria como patrimônio orientador de todas as práticas sanitárias e não seria construída somente com base em uma perspectiva centrada no social ou na epidemiologia, mas no uso diversificado de distintos saberes. Ao mesmo tempo, a compreensão dessa articulação de conhecimentos nega, portanto, a existência automática, e em princípio, de uma dominância da determinação social no processo saúde/doença. Com cer- 
teza, há hierarquia ao se produzir um dado fenômeno sanitário. No entanto, esta hierarquia será, necessariamente, situacional e variável e jamais predeterminada.

Tampouco a análise e a investigação de processos saúde/doença/intervenção são monopólios da saúde coletiva. Como também não o são os métodos de investigação fundados na epidemiologia, na antropologia, na sociologia ou na biologia. Cada modo de produção de saúde é composto por uma dada combinação - qualitativa e quantitativa - de práticas. A combinação destes modos criaria modelos distintos, ainda quando alguns autores utilizem essas expressões em sentido equivalente. A saúde coletiva ou a saúde pública, como núcleo, ou a vigilância à saúde seu principal modelo de intervenção, ou a clínica seriam um entre outros modos de se produzir saúde. As políticas de saúde e modelos de atenção resultariam de diferentes combinações destes modos e destas práticas.

Os distintos modos de se produzir saúde apresentam-se com antagonismos; mas também têm aspectos complementares já que se fundamentam em teoria e práticas não necessariamente excludentes.

Identificam-se quatro modos básicos para se produzir saúde: a) transformações econômicas, sociais e políticas resultando em padrões saudáveis de existência, dificultando o surgimento de enfermidades. Cidades saudáveis tem denominado este modo de produção referente à promoção à saúde (WHO,1991); b) vigilância à saúde voltada para a promoção e prevenção de enfermidades e morte; c) clínica e reabilitação em que se realizam práticas de assistência e de cuidados individuais de saúde e d) atendimento de urgência e de emergência, em que práticas de intervenção imediatas, em situações limites, evitam morte e sofrimento.

Não há limites precisos ou rígidos entre os diferentes modos de produção. Todos utilizam práticas de promoção e de prevenção, ações clínicas de reabilitação e de cuidados. O que varia é a ênfase com que são utilizados. Assim, a clínica vale-se predominante de práticas de atenção ao indivíduo, ainda quando a clínica, para ganhar em eficácia, necessite incorporar o social e o subjetivo e operar com algumas práticas de prevenção e de promoção à saúde. Do mesmo modo, é impossível praticar saúde pública sem o auxílio da clínica, pela atenção individual em programas coletivos ou vice-versa. No entanto, na vigilância à saúde (saúde pública) predominam práticas de promoção e de prevenção. Parte importante das ações de promoção escapam ao próprio campo da saúde e ao núcleo da saúde pública. Limites borrados, como foi assinalado anteriormente, estão também entre as práticas incorporadas por estes diferentes modos de produzir saúde.

A saúde seria, pois, o resultado de um processo de produção. Um efeito algumas vezes desejado e buscado, com o sentido dado por Sartre (1963) ao termo, um vir-a-ser, um devir, um bem a ser conquistado conforme bem o precisou Cecília Minayo (1991). Indicando um processo sobre o qual intervêm práticas sociais, está relacionado tanto a necessidades sociais quanto a práticas de intervenção e controle. A clínica e a saúde coletiva produzem sempre saúde e controle. E o objeto sobre o qual se intervém indica o compromisso assumido pelas práticas sanitárias. No caso dos sistemas de saúde este objeto é representado pela doença ou por situações que a potencializem, quer digam respeito ao indivíduo ou ao meio. $\mathrm{O}$ objetivo, o fim, ou a finalidade desses serviços é a produção de saúde.

Tais idéias acima desenvolvidas se contrapõem às de alguns autores que sugerem reformular o paradigma biomédico mediante um deslocamento do objeto de intervenção dos sistemas de saúde. Deixar-se-ia de trabalhar com a doença para se operar com a saúde. Ora, tal propósito aparece como um contra-senso dentro da perspectiva teórica deste artigo já que a saúde é vista como um produto, um fim, um resultado almejado, um objetivo. O objeto sobre o qual intervém toda ou qualquer prática de saúde é a doença ou a potencialidade de se adoecer ou de morrer. Almeida Filho e Paim (1999) sugerem una salud coletiva previsional o, si nos permiten, pre-visionaria, es decir, una salud coletiva capaz de proponer visiones, formas, figuras y escenarios.

O que se está ressaltando, contudo, é que o objetivo de se produzir saúde seria comum a todas as práticas em saúde e não somente àquelas vinculadas à saúde pública. Toda prática sanitária, em alguma medida, seria levada a oferecer algum valor de uso, no caso, algum coeficiente de bem-estar, ainda que junto se produzam também iatrogenia e controle social. $\mathrm{Ne}$ nhum bem ou serviço pode desvincular-se completamente da obrigação de atender a necessidades sociais. O que varia é o grau e a qualidade com que são oferecidas. Voltar-se-ia, portanto, à pergunta sobre o objeto da saúde cole- 
tiva. Para responder a esta questão haveria que se investigar sua história concreta. Afinal o recorte do objeto da saúde coletiva é bastante influenciado pela dinâmica política (Donnangelo, 1983) e varia conforme a correlação dessas forças, a ação do Estado e dos distintos atores sociais, que atuam no setor.

\section{Para reconstruir o núcleo de saberes e práticas da saúde coletiva: algumas sugestões para debate}

A saúde coletiva e a defesa da vida (Campos GWS,1991). Em primeiro lugar é preciso assumir explicitamente que a saúde pública é uma construção social e histórica e que, portanto, depende de valores, ou seja, é resultante da assunção e da luta de alguns valores contra outros. Nesse sentido, sugere-se que os sanitaristas e demais profissionais de saúde assumam explicitamente uma visão de mundo fundada na radical defesa da vida das pessoas com as quais trabalhem. Isso implica a busca da construção de condições sociais que possibilitem aos especialistas em saúde coletiva trabalhar com autonomia relativa tanto em relação ao Estado, quanto a partidos políticos, ideologias e outras racionalidades técnicas. Assim, caberia ao sanitarista posicionar-se sobre a existência ou não de saberes e de modos concretos para se enfrentar tal ou qual problema de saúde; argüindo contra os economistas e políticos em defesa da vida de grupos expostos a riscos. Não deixar aos economistas a argumentação sobre inviabilidade econômica, e aos políticos, desculpas fundadas no pragmatismo dos que lutam pelo poder, mas exercita uma ética assentada no compromisso explícito com a vida.

Não que a perspectiva acima venha a ter sempre a última palavra, mas é preciso reconhecer que a sociedade ganharia com promotores públicos, em princípio, comprometidos com a defesa da vida. Ou seja, com intelectuais orgânicos (Gramsci, 1978) coerentes, em seus discursos e em suas práticas, com uma teoria de produção da saúde. É óbvio que a resultante desses processos nunca será o projetado pelo discurso sanitário puro, mas uma síntese de distintas racionalidades.

Há um segundo aspecto a ser reforçado: reconhecer que a saúde é um valor de uso. Valor de uso com o sentido que originalmente Marx (1985) atribuiu ao conceito, no volume primeiro de $O$ capital. Valor de uso entendido como a utilidade que bens ou serviços têm para pessoas concretas vivendo em situações específicas. Ninguém conseguiria fazer circular uma mercadoria sem valor de uso. A saúde, mesmo quando entendida como um bem público, ou seja, quando lhe é socialmente retirada o caráter de mercadoria, como acontece no Sistema Único de Saúde, já que é produzida como um direito universal e não em função de seu valor de troca, mesmo nestes casos, ela conserva o caráter de valor de uso.

A utilidade de um bem ou serviço não é um dado intrínseco a ele, mas é socialmente construída. Resultando, portanto, da ação de distintos atores sociais em sentido nem sempre convergente, marcando cada produto com um certo valor de uso. Assim, o valor da vida varia conforme a época, a classe e o contexto social: expressa-se sob a forma de necessidades sociais. Necessidades sociais são significadas em bens ou serviços a que tal ou qual segmento social atribui alguma utilidade.

Foucault (1995) afirmava que uma das manifestações do poder era a capacidade de produzir verdades. Em analogia, poder-se-ia afirmar que a capacidade de produzir necessidades sociais é uma manifestação concreta do poder dos distintos grupos e segmentos sociais (Campos, 2000). Nesse sentido, tanto as equipes de saúde quanto a sociedade deveriam explicitamente cuidar da produção de valores de uso e de sua expressão pública sob a forma de necessidades sociais. Enganam-se aqueles que atribuem ao poder dominante a capacidade exclusiva de sempre produzir necessidades sociais. Por mais poderoso que sejam o Estado e mercado, jamais essas instâncias conseguiram desconhecer a dinâmica social que resulta na construção de necessidades. Ainda quando relegam desejos e interesses dos usuários, ou o discurso da saúde coletiva, esses elementos acabam por mostrar sua lógica. Em alguma medida, os de baixo metem sua colher de pau no cozido das necessidades sociais.

O que se argumenta é que caberia aos trabalhadores e aos usuários, a partir de seus próprios desejos e interesses, apoiando-se em uma teoria sobre a produção de saúde, tratar de construir projetos e de levá-los à prática; objetivariam então a concretização de determinados valores de uso, expressos sob a forma de necessidades, bem como dos meios necessários para atendê-las. Uma luta sem resultados prévios assegurados. É contrária à razão dialética a análise que atribui exclusividade de efeitos à 
racionalidade ou ao poder hegemônico. O poder hegemônico é o dominante e não o único. Os dominados também interferem na dinâmica social, particularmente quando se trata da alteração de valores. Ora, valores são os alicerces das estruturas e as estruturas são produtoras e garantidoras de valores. A alteração de valores ressalta a inadequação social e histórica de estruturas ultrapassadas, aumentando as possibilidades de mudança.

Para finalizar, valeria um esforço concentrado da saúde coletiva objetivando tornar mais democrática e participativa a definição de valores de uso e de necessidades sociais.

A saúde coletiva e o fortalecimento dos sujeitos. Co-participar da produção de necessidades sociais exige iniciativa política e capacidade de reflexão crítica. Como a saúde coletiva poderia contribuir para diminuir o coeficiente de alienação das pessoas?

Sartre (1963) falava em serialidade, referindo-se a grupos que repetiam comportamentos condicionados por estruturas ou valores hegemônicos. Entretanto apontava para a possibilidade da construção de grupos sujeitos, agrupamentos aptos a lidar com essas determinações e condicionamentos de forma mais livre. E assim, considerando as limitações do contexto, criar-se-iam situações mais justas e democráticas. Mas e a saúde coletiva teria algo a ver com isso?

Basaglia aproveitou-se desta linha de reflexão aqui tecida para repensar políticas e práticas em saúde mental. Poder-se-ia adaptar algo de suas conclusões para a saúde pública? Amarante (1996) sintetizou bem a perspectiva metodológica com que Basaglia trabalhou: Se a doença é colocada entre parênteses, o olhar deixa de ser exclusivamente técnico, exclusivamente clinico. Então, é o doente, é a pessoa o objetivo do trabalho, e não a doença. Desta forma a ênfase não é mais colocada no processo de cura, mas no processo de invenção da saúde e de reprodução social do paciente.

A perspectiva é de saída do objeto ontologizado da medicina - a doença - e entrada, em seu lugar, de um sujeito. No caso da clínica, o doente; no caso da saúde coletiva, uma coletividade específica. Vale enfatizar, que Basaglia não se referia a um enfermo em geral, mas a um sujeito concreto, social e subjetivamente constituído. O mesmo se aplicaria a uma saúde coletiva que se pretendesse construtiva: deveria trabalhar com grupos concretos, social e culturalmente constituídos. Toda a ênfase seria pos- ta sobre a existência concreta de sujeitos e sobre a possibilidade de se inventar saúde para esses enfermos, no caso da clínica; e para grupos expostos a possibilidade de enfermar-se, para a saúde pública.

Inventar saúde para Basaglia (1985) implicaria mais do que uma invenção técnica, já que ele ligava essa noção à de reprodução social do paciente. Reprodução social entendida como exercício de cidadania e de participação social. Em saúde pública poder-se-ia trabalhar com a idéia de mudança tanto das estruturas, sua democratização, e da normas de direito, quanto da capacidade reflexiva e da iniciativa dos sujeitos individuais e coletivos. A reconstrução da saúde coletiva passaria por um deslocamento de ênfase: antes fora a doença, depois as estruturas, agora se trataria também de valorizar o fortalecimento dos sujeitos individuais e coletivos. No entanto, o deslocamento de ênfase não poderia significar abandono das outras dimensões. Como produzir sujeitos saudáveis sem considerar as doenças ou a possibilidade de enfermar-se? Ou sem avaliar criticamente aspectos estruturais (ambiente, leis, normas )?

A perspectiva de fortalecimento dos sujeitos foge à antidialética positivista de medicina que fica com a doença descartando a responsabilidade com a história dos sujeitos concretos; e supera o estruturalismo da saúde pública tradicional que delega ao Estado e ao aparato técnico quase toda a responsabilidade pela produção de saúde.

Concluindo, é preciso investir não somente dimensão corporal dos sujeitos conforme tradição da saúde pública (vacinação, por exemplo), mas também pensá-los como cidadãos de direito e donos de uma capacidade crítica de reflexão e de eleição mais autônoma de modos de levar a vida.

Nesse sentido, a atual ênfase da saúde pública em combater determinados estilos de vida (WHO, 1991), ainda que aparentemente reconhecendo a existência de pessoas concretas, não deixa de ser uma forma moralista e normativa de abordagem, já que os grupos a quem se destinam essas intervenções não são incorporados na construção ativa de modos de vida. Por exemplo, escolher entre longevidade e prazer é um direito inalienável da pessoa humana. A participação na administração das relações entre desejos, interesses e necessidades sociais é condição sine qua non para a democracia e para a construção de sujeitos saudáveis (Campos, 2000). 


\section{Referências bibliográficas}

Agudello FS e Nunes ED 1991. Presentación. In Franco S Nunes ED, Breilh J e Laurell AC (org.). Debates en medicina social. Ed. OPS, Quito.

Almeida Filho N e Paim JS 1999. La crisis de la salud pública y el movimiento de la salud colectiva en Latinoamérica. Cadernos Médicos Sociales, n. 75:5-30.

Amarante Paulo 1996. O ovo da serpente. Fiocruz, Rio de Janeiro.

Barata RB e Barreto ML 1996. Algumas questões sobre o desenvolvimento da epidemiologia na América Latina. Ciência e Saúde Coletiva, v.1, n.1:70-79.

Basaglia F 1985. A instituição negada: relato de um hospital psiquiátrico. 2a ed. Ed. Graal, Rio de Janeiro.

Bourdieu P 1983. O campo científico. In Ortiz R (org.) Pierre Bourdieu. Editora Ática, coletânea Grandes Cientistas Sociais.

Bourdieu P 1992. A economia das trocas simbólicas. Ed. Perspectiva, São Paulo.

Campos GWS 1991. A saúde pública e a defesa da vida. Editora Hucitec, São Paulo.

Campos GWS et al. 1997. Análise crítica sobre especialidades médicas e estratégias para integrá-las ao Sistema Único de Saúde (SUS). Cadernos de Saúde Pública, 13(1):141-144.

Campos GWS 2000. O anti-Taylor e o método Paidéia: a produção de valores de uso, a construção de sujeitos e a democracia institucional. Tese de livre-docência. Campinas/SP, Faculdade de Ciências Médicas da Universidade de Campinas (UNICAMP).

Carvalho AI 1996. Da saúde pública às políticas saudáveis - saúde e cidadania na pós-modernidade. Ciência e Saúde Coletiva, vol.1, n.1:104-121.

Chaui M 1989. Merleau-Ponty - vida e obra. In MerleauPonty - textos selecionados. Os Pensadores. Nova Cultural, São Paulo.

Deleuze G e Guattari F 1976. O anti-Édipo: capitalismo e esquizofrenia. Ed. Imago, Rio de Janeiro.

Donnangelo MCF 1976. Saúde e sociedade. Ed. Duas Cidades, São Paulo.

Donnangelo MCF 1983. A pesquisa na área de saúde coletiva no Brasil - a década de setenta. In ABRASCO, Ensino da Saúde Pública, Medicina Preventiva e Social no Brasil, vol. 2:17-36.

Foucault M 1995. O sujeito e o poder. In P Rabinow \& H Dreyfus. Foucault uma trajetória filosófica: para além do estruturalismo e da hermenêutica. Ed. Forense, Rio de Janeiro.

Freud S 1969. Novas conferências introdutórias sobre a psicanálise. In Edição standard brasileira das obras psicológicas completas de Sigmund Freud. vol. XXII. Imago, Rio de Janeiro.

Gramsci A 1978. Concepção dialética da história. Ed. Civilização Brasileira. Rio de Janeiro.

Hegel GWF 1974. A fenomenologia do espírito. Os Pensadores. Ed. Abril, São Paulo.

Lefebvre H 1995. Lógica forma e lógica dialética. Ed. Civilização Brasileira, Rio de Janeiro.
Marx K 1985. O capital: crítica da economia política. vol. I, livro primeiro. Ed. Nova Cultural, São Paulo.

Marx K e Engels F 1996. A ideologia alemã: I- Feuerbach. 10a ed. Editora Hucitec, São Paulo.

Matui J 1995. Construtivismo: teoria construtivista sociohistórica aplicada ao ensino. Ed. Moderna, São Paulo.

Mendes EV 1993. Distrito sanitário. O processo social de mudança das práticas sanitárias do Sistema Único de Saúde. Editora Hucitec/Abrasco, São Paulo.

Merleau-Ponty M 1990. Merleau-Ponty na Sorbonne: resumo de cursos. Ed. Papirus, Campinas.

McNeill D e Freiberger P 1993. Fuzzy Logic. Ed. Simon \& Schuster, Nova York.

Minayo MC 1991. Um desafio sociológico para a educação médica. Revista Brasileira de Educação Médica (ABEM) 15(1):25-32

Nunes ED 1986. Tendencias y perspectivas de las investigaciones en ciencias sociales y la América Latina: una visión general. In Nunes ED (org.). Ciencias sociales y salud en la America Latina: tendencias y perspectivas. Ed. OPS-CIEU, Washington-Montevidéu.

Nunes ED 1996. Saúde coletiva: revisitando a sua história e os cursos de pós-graduação. Ciência \& Saúde Coletiva, vol.1, n.1:55-69.

Nunes ED 1998. Saúde coletiva: história e paradigmas. Interface: Comunicação, Saúde e Educação, vol. 3:107116.

Ogden T 1996. Os sujeitos da psicanálise. Ed. Casa do Psicólogo, São Paulo.

Onocko Campos RT 1999. O planejamento em saúde sob o enfoque da hermenêutica. Campinas/SP, Departamento de Medicina Preventiva e Social FCM/UNICAMP, (mimeo).

OPAS 1992. La crisis de la salud pública - reflexiones para el debate. Washington.

OPAS 1994. Recursos humanos y sistemas locales de salud. Série Desarrollo de Recursos Humanos, 31. Washington.

Paim JS 1992. La salud colectiva y los desafios de la prática. In La crisis de la salud pública - reflexiones para el debate. Organización Pan Americana de la Salud, Washington.

Sartre J-P 1963. Crítica de la razón dialéctica. Ed. Losada, Buenos Aires.

Testa M 1993. Pensar en salud. Lugar editorial, Buenos Aires.

Valla VV 1999. Educação popular, saúde comunitária e apoio social numa conjuntura de globalização. Cadernos de Saúde Pública, vol. 15/2:15-28.

Van der Veer R e Valsiner J 1996. Vygostsky - uma síntese. Unicarco/Loyola edições, São Paulo.

Vasconcelos EM 1999. Educação popular e a atenção à saúde da família. Hucitec, São Paulo.

WHO 1991. Healthy cities project: a project becomes a movement. WHO Regional Office for Europe, Copenhague. 